\title{
Update of Aetiological Patterns of Adult Gastric Outlet Obstruction in Accra, Ghana
}

\author{
Samuel Essoun', Jonathan C. B. Dakubo² \\ ${ }^{1}$ Department of Surgery, Korle Bu Teaching Hospital, Accra, Ghana \\ ${ }^{2}$ Department of Surgery, University of Ghana Medical School, Accra, Ghana \\ Email: essoun@gmail.com
}

Received 26 July 2014; revised 15 August 2014; accepted 2 September 2014

Copyright (C) 2014 by authors and Scientific Research Publishing Inc.

This work is licensed under the Creative Commons Attribution International License (CC BY). http://creativecommons.org/licenses/by/4.0/

(c) (i) Open Access

\begin{abstract}
Background: The aetiology of gastric outlet obstruction globally has evolved from benign to malignant causes, but there seem to be no recent data on the trends in Ghana. The aim was, therefore, to identify the current patterns in the aetiology of gastric outlet obstruction in the adult population in Ghana. Methodology: This was a retrospective review of all confirmed cases of gastric outlet obstruction in the last decade, spanning from June 2004 to May 2014, that were managed at the Korle Bu Teaching Hospital. Results: A total of 107 patients were managed for gastric outlet obstruction with a male to female ratio of $2.15: 1$ and most of the patients making $71.3 \%$ of cases belonged to the age range of 40 to 60 years. The predominant aetiology for gastric outlet obstruction was found to be gastric cancer (55.140\%), followed by peptic ulcer disease (27.103\%). Conclusion: The aetiology of gastric outlet obstruction in Ghana has evolved from benign to malignant causes, following current global trends. Gastric cancer is now the most important cause of gastric outlet obstruction in Ghana, followed by peptic ulcer disease which predominates as the commonest benign cause.
\end{abstract}

\section{Keywords}

Gastric Outlet Obstruction, Aetiological Trends, Gastric Cancer, Peptic Ulcer Disease

\section{Background}

Gastric outlet obstruction is a clinical and pathophysiological manifestation of a mechanical impediment to the flow of gastric content at the pyloro-duodenal channel which may be complete or partial [1] [2] and often results in significant fluid, electrolytes, acid-base and nutritional deficits as well as weight loss. The varying aetiology can be either benign or malignant, but the mechanism of obstruction may include acute edema, chronic cicatari- 
zation and fibrosis, an obstructing mass or an extrinsic compression at the pyloro-duodenal channel.

The aetiological patterns of gastric outlet obstruction are changing globally. The most frequent cause has changed with the discovery and effective treatment of Helicobacter pylori, a proven cause of peptic ulcer disease. Prior to the 1970s, benign disease was responsible for the majority of cases of gastric outlet obstruction in adults, while malignancies accounted for only 10 to 39 percent of cases [3] [4]. However, recent data from elsewhere suggests malignancies causing $50 \%$ to $80 \%$ cases [3]-[6]. In 1972, Badoe reported that chronic duodenal was the predominant cause of gastric outlet obstruction in the Korle Bu Teaching Hospital in Accra, Ghana [7].

Although some reports suggest peripancreatic cancers as the most common malignant etiology with a frequency of $15 \%-20 \%$ [1] [8], several other reports suggest gastric cancers are the most frequent cause of gastric outlet obstruction [2] [4] [9] [10].

There is no current data on the aetiological patterns of gastric outlet obstruction in Ghana. The rationale of this review is therefore to document what pertains in the Korle Bu Teaching Hospital in Accra, Ghana almost four decades since the last documented aetiological trends for gastric outlet obstruction.

Aim: To identify the current patterns in the aetiology of gastric outlet obstruction in the adult population in Ghana.

\section{Methodology}

This is a retrospective review of patients with confirmed gastric outlet obstruction seen and managed in the Department of Surgery of the Korle Bu Teaching Hospital over the last decade. The period under review is from June 2004 to May 2014.

The data for the study was obtained from the case logs in the operating theatres and also the admissions and discharges logs on the four general surgical units of the department. Key data obtained include the age, sex, the primary cause of gastric outlet obstruction and the treatment offered the patient. The data obtained was analyzed and the key results compared to patterns previously reported in the same hospital and in other countries.

Study centre: The review was carried out in the Korle Bu Teaching Hospital, a tertiary hospital which is located in the South-western part of Accra, which is the capital city of Ghana in West Africa. The hospital is the major referring centre in Ghana and receives patients from all over the country as well as patients from neighboring West African countries.

\section{Results}

During the period from January 2004 to July 2014, a total of 107 adult patients were diagnosed and managed for gastric outlet obstruction in the Korle Bu Teaching Hospital. The patients' ages ranged from 14 to 92 years. The overall modal age group was 60 - 69, although cumulatively 76 patients $(71.03 \%$ of the cases) were within the ages of 40 to 69 years. However the age distribution by sex reveals a modal age group of $60-69$ years for males and 40 - 49 for females.

Overall, most of the gastric outlet obstruction was caused by malignancies making up $72.897 \%$ of all cases while benign diseases were responsible for $27.103 \%$. The aetiologies included gastric carcinoma (55.14\%), peptic ulcer disease (25.234\%), pancreatic head carcinoma (13.084\%) and miscellaneous causes (6.542\%). Table 1 and Figure 1 show the distribution across the different age groups. The miscellaneous causes included primary duodenal tumor, proximal jejunal tumor, adhesions involving the duodenum, and abdominal tuberculosis involving the duodenum.

The sex distribution showed a male preponderance for gastric outlet obstruction across all the various causes with males representing $68.224 \%$ of cases and females, $31.776 \%$ of cases as shown in Table 2 . With regards to the individual aetiologies and their respective sex distribution, of the patients with gastric cancer $76.271 \%$ were males as against $23.729 \%$ females. Among those who had peptic ulcer disease, $62.963 \%$ were males compared to $37.037 \%$ being females. The male to female sex ratio of those who had pancreatic cancer was $57.143 \%$ male to $42.857 \%$ females and the ratio for the other miscellaneous causes was $42.857 \%$ males to $57.143 \%$ females.

Beyond age 30 years, gastric cancers assume importance as the predominant cause of gastric outlet obstruction in the various age groups. The proportions of affected patients are predominantly males in the respective age groups. However, there seem to be an almost equal proportion in the sex distribution with peptic ulcer disease across the corresponding age groups. 
Table 1. Aetiology of gastric outlet obstruction.

\begin{tabular}{cccccc}
\hline \multicolumn{5}{c}{ Diagnosis } \\
\hline Age & Gastric Cancer & Peptic Ulcer & Pancreatic Cancer & Miscellaneous & Total (\%) \\
\hline$<20$ & 0 & 0 & 0 & 1 & $1(0.935 \%)$ \\
$20-29$ & 0 & 1 & 0 & 1 & $2(1.869 \%)$ \\
$30-39$ & 5 & 4 & 1 & 2 & $12(11.215 \%)$ \\
$40-49$ & 10 & 6 & 7 & 2 & $25(23.365 \%)$ \\
$50-59$ & 11 & 6 & 2 & 1 & $20(18.692 \%)$ \\
$60-69$ & 22 & 5 & 4 & 0 & $31(28.972 \%)$ \\
$70-79$ & 7 & 3 & 0 & 0 & $10(9.346 \%)$ \\
$80-89$ & 3 & 2 & 0 & 0 & $5(4.673 \%)$ \\
$>90$ & 1 & 0 & 0 & 0 & $1(0.935 \%)$ \\
TOTAL & $59(55.14 \%)$ & $27(25.234 \%)$ & $14(13.084 \%)$ & $7(6.542 \%)$ & $107(100.002 \%)$ \\
\hline
\end{tabular}

Table 2. Sex ratio.

\begin{tabular}{cccc}
\hline & \multicolumn{2}{c}{ Sex } & \\
\hline Age & Female & Male & Total \\
\hline$<20$ & 0 & 1 & 1 \\
$20-29$ & 0 & 2 & 2 \\
$30-39$ & 2 & 10 & 12 \\
$40-49$ & 12 & 13 & 25 \\
$50-59$ & 9 & 11 & 20 \\
$60-69$ & 4 & 27 & 31 \\
$70-79$ & 5 & 5 & 10 \\
$80-89$ & 1 & 4 & 5 \\
$>90$ & 1 & 0 & 1 \\
TOTAL & $34(31.776 \%)$ & $73(68.224 \%)$ & $107(100.00 \%)$ \\
\hline
\end{tabular}

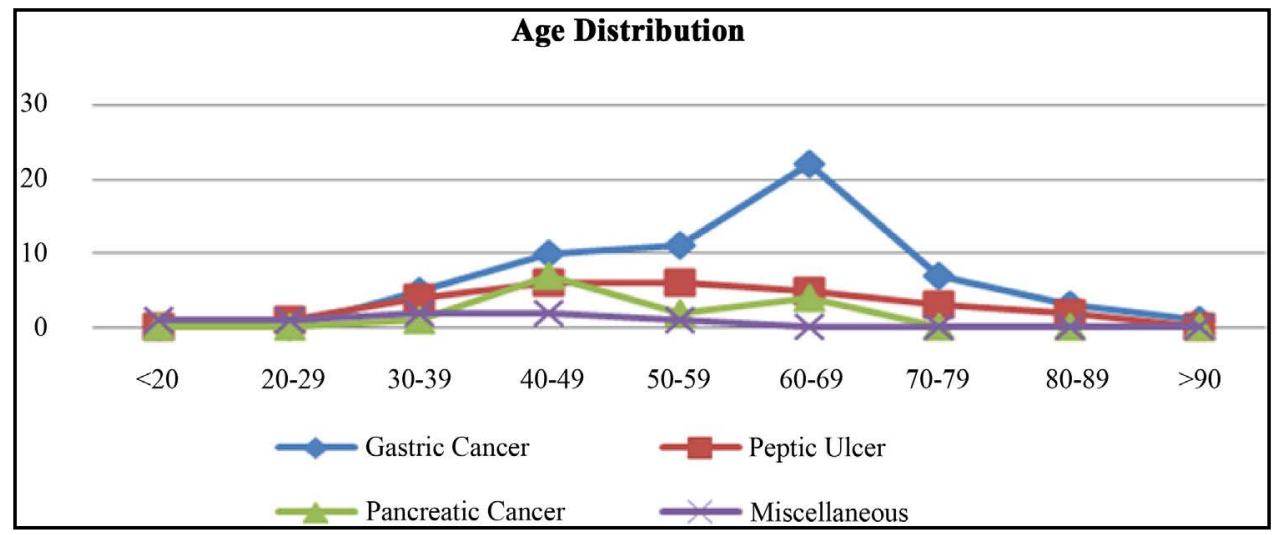

Figure 1. Distribution of the aetiology of gastric outlet obstruction.

The annual trends in the period under review showed a steadily high proportion of cases of gastric outlet obstruction caused by gastric cancer followed by peptic ulcer with a smaller proportion attributable to pancreatic 
cancer and other minor causes as shown in Figure 2.

Comparing the trends over a 5 year period suggested a change in aetiology from peptic ulcer disease in the period between 1967 and 1971 to gastric cancer in the periods of 2004 to 2009 and 2010 to 2014. Whereas peptic ulcer disease formed 71.429\% of all causes of gastric outlet obstruction in the period 1967 to 1971, it formed 26.471\% (2004 to 2009) and 24.658\% (2010 to 2014). There is also an increase in the proportion of patients with gastric cancer aetiology from 23.81\% (1967-1971) to 55.882\% (2004-2009) and 54.795\% (2010-2014). The absolute figures are shown in Table 3 and Figure 3 below.

A total of 90 patients $(84.112 \%)$ had operative treatment for gastric outlet obstruction with a cumulative $36.667 \%$ being gastro-jejunostomy, $28.889 \%$ were partial gastrectomy, $20 \%$ were truncal vagotomy and $14.444 \%$ being triple bypass (cholecysto-jejunostomy, jejuno-jejunostomy and gastro-jejunostomy) due to associated obstructive jaundice (Table 4). Two patients $(1.869 \%)$ were however managed conservatively for acute edema from a pre-pyloric ulcer and the symptoms resolved and 15 patients (14.019\%) had advanced cancer and were never optimized enough for operative intervention.

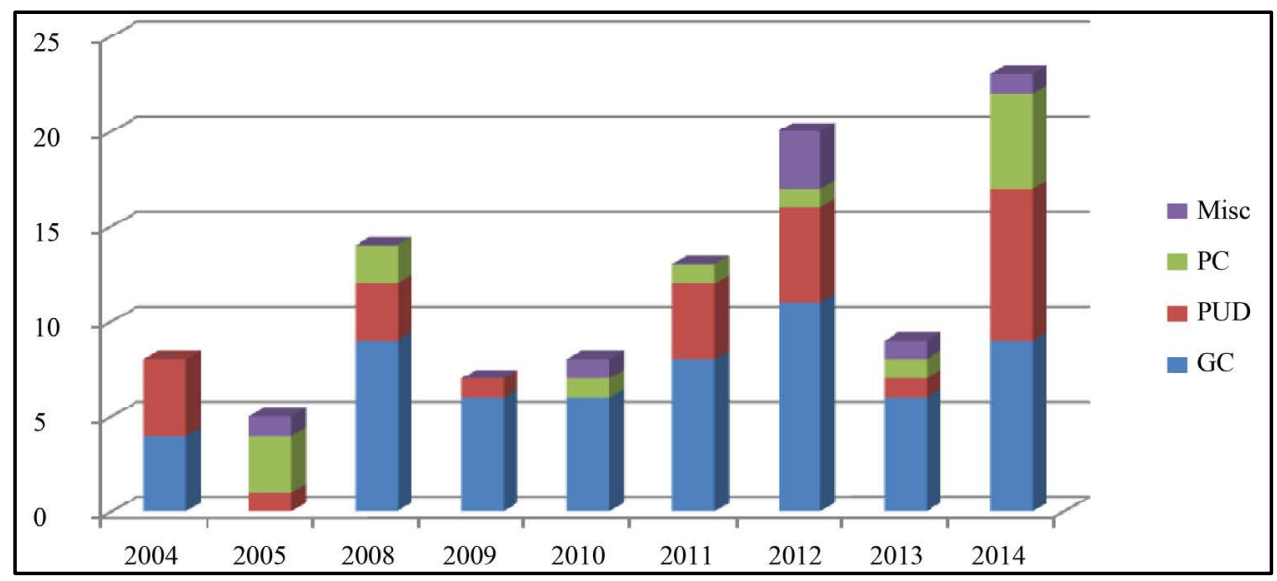

Figure 2. Annual trends (GC-gastric cancer; PUD-peptic ulcer disease; PC-pancreatic cancer; Misc- miscellaneous).

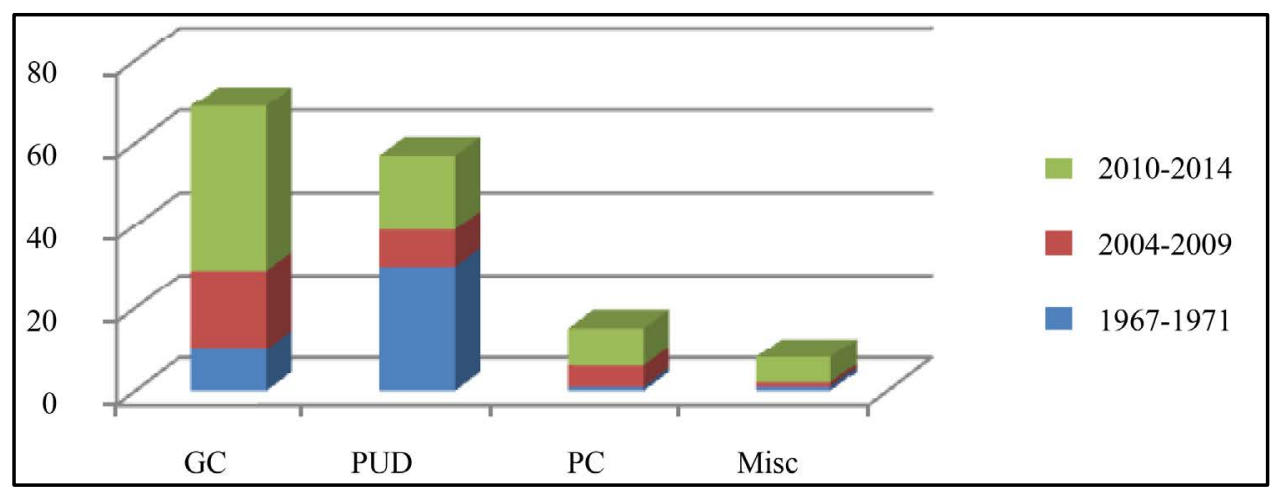

Figure 3. 5 year trends (GC-gastric cancer; PUD-peptic ulcer disease; PC-pancreatic cancer; Miscmiscellaneous).

Table 3. 5 year trends (GC-gastric cancer; PUD-peptic ulcer disease; PC-pancreatic cancer; Miscmiscellaneous).

\begin{tabular}{cccccc}
\hline Period & GC & PUD & PC & Misc & Total \\
\hline 1967-1971 Badoe (1972) & 10 & 30 & 1 & 1 & 42 \\
$2004-2009$ & 19 & 9 & 5 & 1 & 34 \\
$2010-2014$ & 40 & 18 & 9 & 6 & 73 \\
\hline
\end{tabular}


Table 4. Summary of operative procedures done.

\begin{tabular}{ccc}
\hline Procedure & Frequency & Percentage (\%) \\
\hline Gastrojejunostomy for Gastric Cancers & 27 & 30.0 \\
Gastrojejunostomy for Duodenal and lesions & 6 & 6.667 \\
Partial Gastrectomy for Peptic Ulcer & 7 & 7.778 \\
Partial Gastrectomy for Gastric cancers & 19 & 21.111 \\
Truncal Vagotomy with Gastrojejunostomy & 18 & 20.0 \\
Triple Bypass & 13 & 14.444 \\
Total & 90 & 100 \\
\hline
\end{tabular}

\section{Discussion}

Gastric outlet obstruction has evolved in aetiology over the past few decades. The predominant cause was hitherto peptic ulcer disease as has been widely reported in various English language literature both locally and in the west. Prior to the 1970s, benign disease represented by peptic ulcer disease was responsible for the majority of adult cases while malignant disease accounted for only 10 to 39 percent of cases of gastric outlet obstruction [3] [4]. In 1972, Badoe found chronic duodenal ulcer representing 67\% of cases (and pre-pyloric gastric ulcer$5 \%$ ) as the predominant cause of gastric outlet obstruction in the Korle Bu Teaching Hospital in Accra, Ghana [7]. This report has been and remains the only local report on aetiological trends of this condition.

With an improved understanding of the aetio-pathogenesis of peptic ulcer disease and the discovery of Helicobacter pylori which is implicated in the pathogenesis, the advent of effective eradication of Helicobacter pylori infection can give long-term ulcer remission, reduce recurrence, prevent recurrent ulcer bleeding and may aid resolution of pyloro-duodenal stenosis in some cases [11]. It is even suggested that Helicobacter pylori eradication may improve the resolution in obstructive ulcer cases with colonization [12].

In this review, a total of 107 patients with gastric outlet obstruction were diagnosed and offered various treatments. The ages ranged between 14 to 92 years with an overall modal age group of 60 to 69 years although $71.03 \%$ of the patients were in the age range of 40 to 69 years old. This shows a demographic-age phenomenon with $20.6 \%$ of Ghana's population currently older than 40 years [13]. This is the age bracket associated with increased incidence of cancers in general.

The age and sex modal distribution was 60 to 69 years for males and 40 to 49 for females. Most of the patients belong to the 40 to 69 age group and made up $70.97 \%$ of all females and $69.84 \%$ of male patients. The exact reason for this observation is not clear.

Overall, this study shows that males are more affected than females in a ratio of approximately 2:1. These demographics compare to what has been reported where most of the patients are in the fifth and sixth decades [2] [4]. This however was at variance with a review in Tanzania where most of the patients were in the fourth decade [9]. The reasons for the male preponderance may be attributable to the higher incidence of gastric cancers in the male population hence the presence of a distal advanced gastric cancer is likely to obstruct the pyloric channel.

Most of the patients had malignant cause of the obstruction making up about three-fourths of all causes of gastric outlet obstruction with gastric cancer being the predominant malignant cause and peptic ulcer disease the predominant benign cause. This compares to what is reported in several regional reviews [2] [4] [8] [9].

The total number of cases attributable to peri-pancreatic cancer was however very low in comparison to gastric cancers. The reasons for these low proportions cannot be explained. This picture does not support the suggestion that peri-pancreatic cancer is the most important malignant aetiology for gastric outlet obstruction [1].

It was observed in our study that over $44.444 \%$ of our patients with malignant disease had a palliative bypass rather than curative resections because they often presented late with advanced disease and $14.019 \%$ of patients could not have the benefit of operative intervention due to poor clinical state.

\section{Limitations}

Since the study is a retrospective one, and the data obtained from the operating room log book and the admis- 
sions and discharges logs from the surgical wards, details regarding the presenting symptoms were not captured in the study. However, in the follow up prospective study on this subject, details of the clinical presentation, endoscopic features, the exact type of surgical treatment, the long-term disease related morbidity or surgery related morbidity and the quality of life of individual patients will be evaluated.

\section{Conclusions}

The aetiology of gastric outlet obstruction in Ghana has evolved from benign to malignant causes following current global trends. Gastric cancer is now the most important cause, followed by peptic ulcer disease which predominates as the commonest benign cause.

The results from the review emphasize the need for accurate data collection on gastric outlet obstruction and enhance the need for a prospective study on this subject. With gastric cancers becoming prominent, there is an urgent need for a study into the epidemiology, aetiology and risk factors for gastric cancers in Ghana, while public health education and early diagnosis cannot be overemphasized.

\section{References}

[1] Tendler, D.A. (2002) Malignant Gastric Outlet Obstruction: Bridging Another Divide. The American Journal of Gastroenterology, 97, 4-6. http://dx.doi.org/10.1111/j.1572-0241.2002.05391.x

[2] Samad, A, Whanzada, T.W. and Shoukat, I. (2007) Gastric Outlet Obstruction: Change in Etiology. Pakistan Journal of Surgery, 23, 29-32.

[3] Johnson, C.D. (1995) Gastric Outlet Obstruction-Malignant until Proven Otherwise. The American Journal of Gastroenterology, 90, 1740.

[4] Shone, D.N., Nikoomanesh, P., Smith-Meek, M.M. and Bender, J.S. (1995) Malignancy Is the Most Common Cause Of Gastric Outlet Obstruction in the Era of H2 Blockers. The American Journal of Gastroenterology, 90, 1769-1770.

[5] Johnson, C.D. and Ellis, H. (1990) Gastric Outlet Obstruction Now Predicts Malignancy. British Journal of Surgery, 77, 1023-1024. http://dx.doi.org/10.1002/bjs.1800770923

[6] Chowdhury, A., Dhali, G.K. and Banerjee, P.K. (1996) Etiology of Gastric Outlet Obstruction. The American Journal of Gastroenterology, 91, 1679.

[7] Badoe, E.A. (1972) Gastric Outlet Obstruction in Adults-Ktrle Bu Teaching Hospital, Accra. The West African Medical Journal and Nigerian Medical \& Dental Practitioner, 21, 154-158.

[8] Sohn, T.A., Lillemoe, K.D. and Cameron, J.L. (1999) Surgical Palliation of Unresectable Periampullary Adenocarcinoma in the 1990s. Journal of the American College of Surgeons, 188, 658-666. http://dx.doi.org/10.1016/S1072-7515(99)00049-6

[9] Misra, S.P., Dwivedi, M. and Misra, V. (1998) Malignancy Is the Most Common Cause of Gastric Outlet Obstruction Even in a Developing Country. Endoscopy, 30, 484-486. http://dx.doi.org/10.1055/s-2007-1001313

[10] Jaka, H., Mchembe, M.D., Rambau, P.F. and Chalya, P.L. (2013) Gastric Outlet Obstruction at Bugando Medical Centre in Northwestern Tanzania: A Prospective Review of 184 Cases. BMC Surgery, 13, 41. http://dx.doi.org/10.1186/1471-2482-13-41

[11] Ostrow, B. (2007) Peptic Ulcer Disease-The Impact of Helicobacter pylori on Management in the Developing World. Surgery in Africa Monthly Review (SIA), No. 9, April 2007 Edition.

[12] Taskin, V., Gurer, I., Ozyilkan, E., Sare, M. and Hilmioglu, F. (2000) Effect of Helicobacter pylori Eradication on Peptic Ulcer Disease Complicated with Outlet Obstruction. Helicobacter, 5, 38-40. http://dx.doi.org/10.1046/j.1523-5378.2000.00005.x

[13] Ghana Statistical Service (GSS) (2012) 2010 Population and Housing Census, Summary Report of Final Results. 
Scientific Research Publishing (SCIRP) is one of the largest Open Access journal publishers. It is currently publishing more than 200 open access, online, peer-reviewed journals covering a wide range of academic disciplines. SCIRP serves the worldwide academic communities and contributes to the progress and application of science with its publication.

Other selected journals from SCIRP are listed as below. Submit your manuscript to us via either submit@scirp.org or Online Submission Portal.
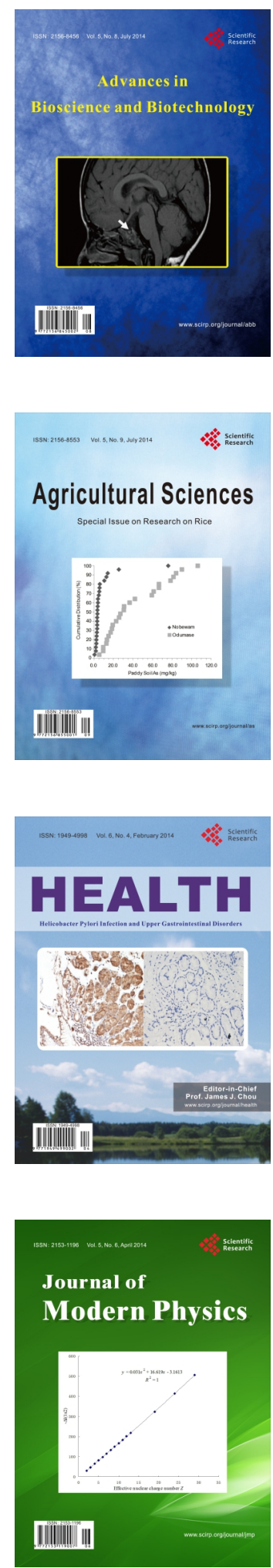
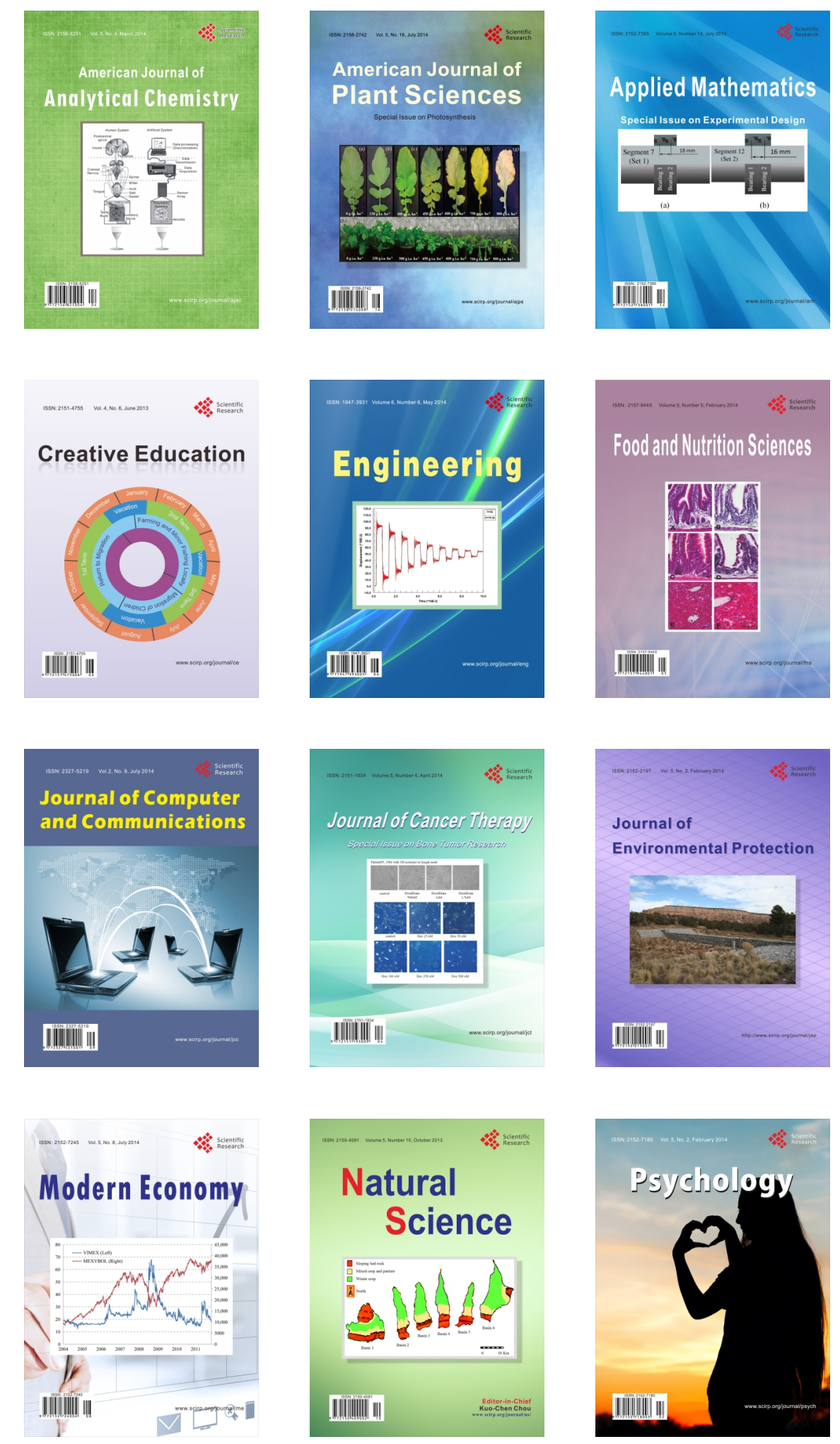